\title{
UNA NUEVA PROPUESTA INTERPRETATIVA DE LA CIUDAD NORTEAMERICANA: EL EJEMPLO DE CANADÁ ${ }^{1}$
}

\author{
Rubén C. Lois González \\ Departamento de Xeografia \\ Universidade de Santiago de Compostela
}

\section{RESUMEN}

En numerosas ocasiones, la literatura geográfica y urbanística ha coincidido al definir un modelo de ciudad norteamericana, diferente del europeo. Este modelo se ha elaborado a partir de una serie de características propias del espacio urbano y del sistema de ciudades representativo de Estados Unidos. No obstante, en la presente contribución se procura analizar este concepto partiendo de los ejemplos de ciudad y desarrollo urbano correspondientes a Canadá, que se comparan con los más conocidos del vecino país del sur. El sistema urbano canadiense es policéntrico y está condicionado por el proceso histórico de colonización del país, como en el resto del continente americano. Las principales poblaciones han hecho gala de diversidad étnica y cultural, lo que constituye un atributo reivindicado desde muy diversas instancias, a diferencia de los problemas de segregación y discriminación de las urbes estadounidenses. En cualquier caso, la ciudad está fragmentada en unidades residenciales autónomas (las comunidades), no existe un auténtico sentido de pertenencia al conjunto urbano y los espacios comerciales e industriales responden a una estricta zonificación. Aquí se observa una

1 Este trabajo es el resultado de una estancia de investigación del autor en las Universidades de Calgary y Lethbridge, en la provincia de Alberta, a principios de 2012, durante dos meses. La estancia fue posible gracias a una beca concedida por el Instituto de Estudios Canadienses, dependiente del gobierno de dicho país. Durante dicha estancia el autor tuvo la oportunidad de colaborar con geógrafos urbanos de ambas instituciones (en especial W.K.D. Davies e I. Townshead), así como de recabar información para la investigación que aquí se presenta. 
morfología y estructura urbanas comunes a toda Norteamérica, si bien las urbes en Canadá mantienen una serie de signos diferenciales, basados en la tolerancia y el bienestar, que no se perciben con tanta claridad a lo largo de Estados Unidos.

Palabras clave: ciudad norteamericana, sistema urbano, sky line, comunidad residencial, multicultural, ciudad fragmentada

\begin{abstract}
Many times, geographical and urban literature has coincided to define a model of North American city, different from the European. This model was developed from a number of typical characteristics of urban space and from the representative U.S city system. Nevertheless, this contribution expects to analyze this concept based on the examples of city and urban development corresponding to Canada, which are compared with the best known of its southern neighbor. The Canadian urban system is polycentric and it is conditioned by the historical process of colonization of the country, as in the rest of the American Continent. The main populations have boasted of ethnic and cultural diversity, which is an attribute reclaimed from many institutions, different from problems of segregation and discrimination of American cities. In any case, the city is fragmented into autonomous residential units (communities), there is not a real sense of belonging to urban complex, and commercial and industrial spaces represent a strict zoning. Here can be observed a morphology and urban structure common throughout North America, although cities in Canada have a series of differential signs, based on tolerance and welfare, which are not noticed so clearly throughout the United States.
\end{abstract}

Key Words: North American city, urban system, sky line, residential community, multicultural, fragmented city.

El objetivo fundamental de este trabajo consiste en comprender la ciudad norteamericana, su funcionamiento y dinámica interna. A este respecto la elección de Canadá y no de Estados Unidos está motivada por la fuerte tradición de Geografía (social) urbana cultivada en ese país, porque sus ciudades muestran unas características comunes con las estadounidenses (ciertamente existe la urbe norteamericana) y también debido al carácter más pacífico, auténticamente multicultural y preocupado por mantener el «Estado de Bienestar» (Welfare State) de la ciudadanía canadiense. Para este fin, nos desplazamos varios meses al país, donde se plantea la investigación. A este respecto, el territorio elegido para residir es un típico ejemplo del Canadá anglófono, que ha crecido de manera notable en épocas recientes (gracias en buena medida a la explotación de los enormes yacimientos petroleros de los que dispone) y expresa muy bien los rasgos de la urbanización norteamericana de los últimos cien años: la provincia de Alberta. En 
la misma, tanto Calgary como Lethbridge son ciudades de muy bajas densidades (próximas a las proporcionadas por Los Ángeles), donde su población reside en comunidades bien definidas y apenas se mueve más allá del gran centro comercial (Mall) próximo y de los pubs y restaurantes locales, y en las que el uso del automóvil privado es ampliamente dominante (la práctica totalidad de los desplazamientos, incluso desde el coche se paga y consume el primer café de la mañana).

A lo largo de las próximas páginas se ordena temáticamente, y bajo un discurso académico, una interpretación de la ciudad canadiense, tanto la observada por el autor de forma directa (la lectura de un geógrafo español sobre esta realidad) como la analizada en profundidad por los colegas de Geografía urbana de este país, y que conforman una auténtica escuela de gran reputación en estos estudios (con W.K.D. Davies, L. Bourne, J. Simmons, D., Ley, I. Townshead, etc., como algunos de sus máximos representantes) (Davies, 1993; Bourne, 2005). La exposición que se propone se centrará en cuatro aspectos principales que se consideran básicos para comprender la ciudad y la urbanización en Canadá, y desembocarán en una conclusión final. El primero de ellos plantea la comprensión del sistema urbano del país en un contexto federal. Dicho de otro modo, cómo en un territorio de colosales dimensiones, la existencia de una división provincial con amplias cotas de autogobierno impide que una ciudad dominante (como podría ser el caso de Toronto) se imponga claramente sobre las demás y centralice su influencia sobre toda la nación. El segundo, la noción de ciudad multicultural. Canadá ha sido tradicional tierra de inmigración desde todo el mundo, y el respeto a los derechos (lingüísticos, culturales, religiosos, etc.) de las comunidades minoritarias es un signo de identidad fundamental para el país. En la ciudad canadiense se observa la diversidad, conviven diferentes formas de vestir y comportarse, y el estatus de las comunidades nacionales acaba siendo un símbolo de referencia de la propia urbe (con los casos destacados de Vancouver y Toronto). El tercer apartado se reserva a conocer la organización interna del espacio urbano, a partir de la noción de ciudad fragmentada, que responde a la perfección a la idea que proyecta la estructura urbana en Canadá. El cuarto epígrafe recurre a uno de los conceptos clave acuñados por la Escuela de sociología urbana de Chicago hace casi cien años y se dedica al modo de vida urbano. Una forma de uso de la ciudad muy marcada por el individualismo (algo que choca por completo con las ideas de los europeos del sur) y la importancia adquirida por la comunidad de referencia (bien sea residencial, étnica, religiosa, etc.). En definitiva, nos interesa realizar al mismo tiempo un acercamiento excepcionalista, de estudio de caso único, pero con el enorme bagaje teórico y conceptual que aporta la Geografía urbana contemporánea en su intento por sistematizar la diversidad de realidades ciudadanas a lo largo del mundo. 


\section{EL SISTEMA URBANO DE UN PAÍS FEDERAL: SEMEJANZAS CON OTROS EJEMPLOS}

Un acercamiento a la red de ciudades más importante de Canadá debe partir de la consideración de su semejanza con los modelos proporcionados por otros países nuevos, de fuera de Europa y dimensiones extraordinarias. Así, lo referido a Canadá se aproxima a lo que sucede en Estados Unidos, Brasil o Australia. Si establecemos el paralelismo con los dos primeros, cabe reseñar que estos territorios federales se formaron a partir de las sucesivas oleadas de colonización y, por lo tanto, reforzaron el protagonismo de las urbes portuarias situadas en su parte oriental, más cercana a Europa. En Brasil primero fue la capitalidad de Salvador de Bahía, luego la de Río de Janeiro y más tarde la enorme pujanza económica de Sao Paulo. En todo caso, tres de las principales ciudades del país (junto a Belo Horizonte, Porto Alegre, Recife y Fortaleza las más pobladas) situadas en el litoral atlántico. De forma paralela, en Estados Unidos la urbanización floreció en Nueva Inglaterra (Boston, Nueva York, Filadelfia, Baltimore y Washington, entre otras), y más tarde en la región de los Grandes Lagos (Chicago, Detroit, etc.). En Canadá sucede un poco lo mismo con Montreal y Toronto, separadas al ser respectivamente las dos grandes metrópolis de la comunidad francófona y anglófona. La primacía de ambas ha sido incuestionable hasta el presente en el plano simbólico y funcional, si bien la pujanza de Vancouver en la costa pacífica o de las petroleras Calgary y en menor medida Edmonton empiezan a cuestionar su hegemonía. De hecho, el crecimiento poblacional y sobre todo urbano del país se ha comenzado a desplazar hacia el oeste, rico en recursos, multicultural (con una fuerte presencia de personas de origen asiático) y abierto al nuevo espacio económicamente hegemónico a nivel mundial, el Pacífico (Figura 1). Este proceso es paralelo al observado en Estados Unidos con la intensa urbanización y crecimiento de California (Los Ángeles, San Francisco y San Diego, como grandes metrópolis) y Washington (con la millonaria Seattle a la cabeza).

Además del proceso histórico de ocupación del espacio, en la interpretación del sistema urbano canadiense posee una gran trascendencia la organización federal de la nación. De nuevo, en este caso se observan afinidades indudables con Estados Unidos y Brasil (Bertrand y Sanguin, 1994; Limonad, Haersbaert y Moreira, 2004). La existencia de unas provincias (no estados como en los otros dos ejemplos americanos) dotadas de amplias competencias ha favorecido el crecimiento de una o dos importantes ciudades en cada una de ellas. Incluso en los territorios más septentrionales ha sido la división política la que ha creado los únicos enclaves urbanos de esta consideración (pensemos en Yelowknife en el Territorio del Noroeste o Whitehorse en Yukon). Sin duda, la organización provincial explica cómo se ha formado este enorme país y permite entender buena parte de su sistema de ciudades. Así, Ontario constituiría la base del Canadá anglófono, con la metrópoli 
Figural. Provincias canadienses, sus capitales y otras ciudades con más de 500.000 habitantes.

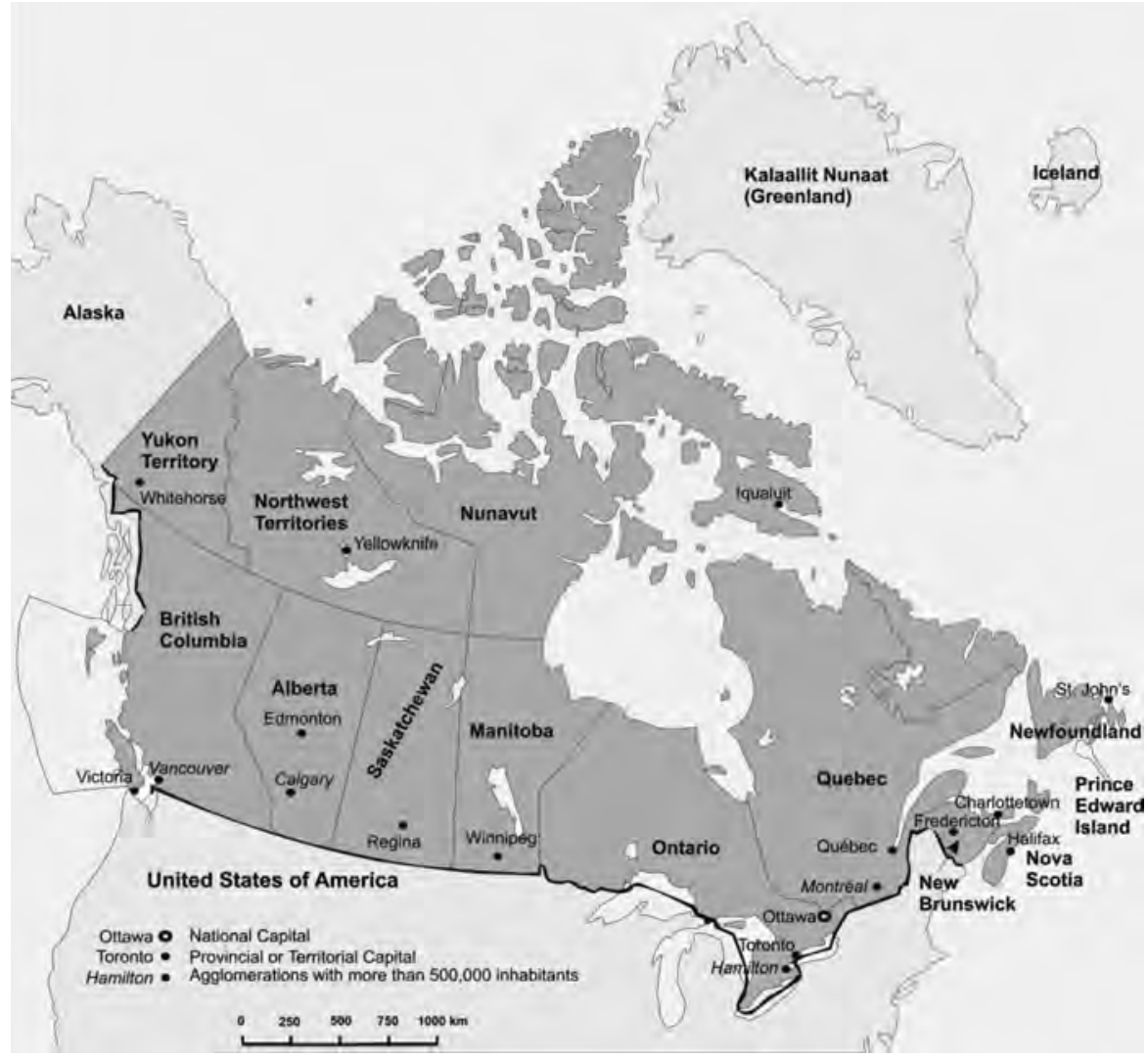

Elaboración propia.

más importante y poblada, Toronto, y un conjunto de urbes relevantes más frecuentes hacia el sur de la provincia (Hamilton, Waterloo, London, St. Catharines, Oshawa y Windsor, todas ellas por encima de los 200.000 hab. en 2011). Por su parte, Quebec concentra una amplia mayoría de la población francófona con el liderazgo económico indiscutible de Montreal, al que acompañan la capital histórica de Quebec y a mucha distancia Sherbrooke (nos referimos a las ciudades con más de 200.000 hab.). Por acuerdo político, la capital federal es una ciudad nueva, construida para cumplir este fin y situada entre Ontario y Quebec, Otawa (con su prolongación francófona de Gattineau), que se convierte en el tercer referente urbano del Este del país, el de la colonización histórica. En el mismo, aparecen otras ciudades destacadas y que vinculan su peso urbano al hecho de actuar como 
capitales provinciales. Nos referimos Halifax (390.328 hab.) en Nueva Escocia, St. John's (196.986 hab.) en Terranova, Charlottetown (64.487 hab.) en la Isla del Príncipe Eduardo y Fredericton (94.268) en New Brunswick (aunque superada en este caso en talla demográfica por Moncton y Saint John). Sin duda, New Brunswick constituye una excepción entre los territorios canadienses del litoral atlántico, ya que la existencia de una fuerte minoría francófona (los descendientes de los primitivos acadianos), y los procesos de desconcentración industrial y portuaria desde el vecino Estados Unidos (en concreto, desde el limítrofe estado de Maine) modifican una red urbana centralizada por la ciudad capital, ofreciendo un modelo donde tres localidades de tamaño similar actúan de referentes principales de la provincia, cada uno de ellos con una personalidad bien definida. En todo caso, a lo largo de este Canadá más histórico las ciudades provinciales acostumbran a ser las que concentran la actividad económica y el empleo, así como una serie de servicios públicos de enorme importancia (hospitales, universidades, comunidades de residencia para personas mayores, etc.)

Si nos desplazamos hacia el Oeste, la explicación del sistema ciudades continúa manteniendo su simplicidad. En Manitoba su capital Winnipeg (730.018 hab.) aglutina las funciones urbanas, careciéndose de otro ejemplo de entidad. En Saskatchewan y en Alberta, sin embargo, la jerarquía urbana es presidida por dos ciudades principales en cada caso, una que ejerce de capital provincial y otra de gran centro económico, una situada más al sur (siguiendo una de las vías de colonización del país hacia el Oeste), y otra más al norte, en un emplazamiento más frío, pero aprovechándose de las disponibilidades de agua y de la existencia de importantes espacios con abundancia de bosques. Nos referimos a Regina (210.556 hab.) y a Saaskatoon (260.600 hab.) en Saskachewan, y a Edmonton (1.159.869 hab.) y Calgary (1.214.839 hab.) en Alberta. Estas dos urbes son mucho mayores debido a la enorme pujanza empresarial y petrolera de este territorio que se extiende hasta las Montañas Rocosas. Por su parte, en la Columbia Británica la histórica Victoria, de fundación española y fuerte tradición británica en la actualidad, continúa siendo la capital provincial (344.615 hab.), si bien el puerto pacífico de Vancouver ha facilitado la consolidación de la tercera ciudad canadiense por volumen de población (2.313.328 hab.), representativa de los espacios del país que miran hacia Asia (China, Japón, Corea, Vietnam, etc.), de donde son originarias las familias de buena parte de su población. Por lo tanto, en Canadá la primacía de Toronto y Montreal es limitada, alcanza de forma difusa el territorio que se sitúa más allá de los límites de Ontario y Quebec, en un sistema urbano donde la construcción provincial del territorio (y el proceso de ocupación del mismo) todavía nos dan las claves principales de la localización de las urbes más importantes. 
A este respecto, Canadá se aproxima a Estados Unidos con la excepción de Nueva York por su extraordinaria proyección como ciudad global. En este vecino del Sur, también California, el Suroeste o el Sur presentan redes urbanas autónomas respecto a Nueva Inglaterra y la región de los Grandes Lagos, donde todavía se mantienen los procesos de metropolitanización más intensos en la actualidad. Por su parte, con Brasil se constatan semejanzas muy relevantes, ya que en este país latinoamericano también las dos ciudades líderes (Sao Paulo y Rio de Janeiro) se encuentran relativamente próximas, si bien sólo ejercen matizadamente su dominio sobre capitales estaduales millonarias como Fortaleza, Recife, Salvador, Manaos, Belo Horizonte o Porto Alegre que no han dejado de crecer en los últimos decenios. El mapa de estados federados en esta nación vuelve a explicar en buena medida la organización del sistema urbano. El segundo factor que lo condiciona es, y ya se ha comentado, la lógica Este-Oeste de ocupación del territorio, que justifica la concentración de todas las ciudades millonarias, con excepción de Manaos, Goiania y Brasilia, en localizaciones no muy alejadas del Atlántico (las menos próximas son los centros de Minas Gerais, un estado de antigua colonización y bien conectado con los principales puertos del país). Además, en Brasil este contraste es más marcado por las dificultades que impone el medio (la extensión de la selva amazónica) al asentamiento en numerosas áreas del interior.

Para finalizar este repaso de la red urbana canadiense, vamos a presentar una tabla (Figura 2), con las principales áreas metropolitanas en 1991 y 2011 , ordenadas por su población. Un comentario de los datos nos muestra el fuerte crecimiento registrado por las ciudades más importantes del país, resultado tanto de su pujanza económica y del hecho de continuar ejerciendo como grandes centros de recepción de inmigrantes, como de un proceso urbanizador reciente que se prolonga hasta la actualidad. De esta forma, se explica el enorme dinamismo de Toronto que pasa de 3.898.933 hab. en 1991 a 5.583.064 hab. en 2011 o de Vancouver que crece de 1.602 .590 a 2.313.328. Incluso núcleos que son considerados estancados, con una débil pujanza, aumentan sustancialmente su volumen de residentes a ojos de un europeo: Montreal ha crecido desde 3.208.970 hab. a 3.824.221 hab. en estos veinte años y Quebec de $645.550 \mathrm{a}$ 765.706. En otros casos, el incremento ha sido muy fuerte, como en las dos principales ciudades de Alberta: Calgary ha pasado de 754.033 hab. a 1.214.839 y Edmonton de 841.132 a 1.159.869. En segundo término, el sistema urbano nos muestra la hegemonía de tres grandes ciudades (Toronto, Montreal y Vancouver) ampliamente millonarias, sobre un segundo escalón formado por otros seis ejemplos en torno al millón de habitantes (desde Otawa-Gattineau, 1.236.324 hab., hasta Hamilton, 721.053 hab.), muy por encima del resto de ciudades que se pueden caracterizar como centros de ámbito regional y provin- 
cial, y son bastante numerosas debido al auge de los núcleos rectores en todo el país. Por último, un comentario regionalizado pone de manifiesto la mayor pujanza reciente de las ciudades localizadas en el centro-oeste de Canadá, que se han visto favorecidas durante los últimos decenios por un mayor desarrollo económico y se han consolidado como centros empresariales de primera magnitud. Esto sucede con Vancouver, destacado nodo portuario transpacífico, con las petroleras Calgary y Edmonton, o con la turística y administrativa Victoria, junto a un significativo número de centros urbanos de la Columbia Británica o Alberta con más de 90.000 residentes (Kelowna, Annostford-Mission, Lethbridge, Kamloops, Chilliwack y Reed Deer). En definitiva, la estructura político-administrativa y las fases de ocupación del territorio siguiendo la lógica este-oeste como condicionantes de un sistema urbano definido por el crecimiento de sus principales poblaciones.

Figura 2. Crecimiento demográfico de las principales aglomeraciones urbanas canadienses.

\begin{tabular}{|c|c|c|c|}
\hline Área Metropolitana & Población 1991 & Población 2011 & \% Crec. \\
\hline Toronto (Ont.) & 3.898 .933 & 5.583 .064 & 43,19 \\
\hline Montréal (Que.) & 3.208 .970 & 3.824 .221 & 19,17 \\
\hline Vancouver (B.C.) & 1.602 .590 & 2.313 .328 & 44,35 \\
\hline Ottawa - Gatineau (Ont./Que.) & 941.814 & 1.236 .324 & 31,27 \\
\hline Calgary (Alta.) & 754.033 & 1.214 .839 & 61,11 \\
\hline Edmonton (Alta.) & 841.132 & 1.159 .869 & 37,89 \\
\hline Québec (Que.) & 645.550 & 765.706 & 18,61 \\
\hline Winnipeg (Man.) & 660.450 & 730.018 & 10,53 \\
\hline Hamilton (Ont.) & 599.760 & 721.053 & 20,22 \\
\hline Kitchener - Cambridge - Waterloo (Ont.) & 356.421 & 477.160 & 33,88 \\
\hline London (Ont.) & 381.522 & 474.786 & 24,45 \\
\hline St. Catharines - Niagara (Ont.) & 364.552 & 392.184 & 7,58 \\
\hline Halifax (N.S.) & 320.501 & 390.328 & 21,79 \\
\hline Oshawa (Ont.) & 240.104 & 356.177 & 48,34 \\
\hline Victoria (B.C.) & 287.897 & 344.615 & 19,70 \\
\hline Windsor (Ont.) & 262.075 & 319.246 & 21,81 \\
\hline Saskatoon (Sask.) & 210.949 & 260.600 & 23,54 \\
\hline Regina (Sask.) & 191.692 & 210.556 & 9,84 \\
\hline Sherbrooke (Que.) & 140.718 & 201.890 & 43,47 \\
\hline
\end{tabular}

Fuente: Censos de Población. Statistics Canada. http://www.statcan.gc.ca. Elaboración propia 


\section{LA CIUDAD MULTICULTURAL}

Un atributo relevante de Canadá es el respeto a las minorías y el empeño puesto por el país en defender la diversidad lingüística, étnica y cultural. De hecho, la sociedad de esta nación considera fundamental preservar los idiomas originarios de las antiguas comunidades de procedencia, desde el francés hasta las hablas amerindias pasando por lenguas tan distintas entre sí como el ucraniano, el japonés, el portugués o el hindú, entre otras muchas. Se debe destacar que esta enorme nación necesitó recurrir durante más de dos siglos a inmigrantes venidos de muy distintos lugares para ocupar vastos territorios vacíos, trabajar en la industria, las minas o la construcción del ferrocarril, y garantizar el poblamiento en espacios con condiciones bioclimáticas extremas. Por eso, y hasta hace relativamente poco, Canadá ha buscado fuerza de trabajo en el exterior y ha tratado de integrarla sin imponer unas normas de adaptación estrictas. Si a esto le añadimos el cuidado que la mayoría anglófona ha tenido por respetar la lengua y cultura francesa de los quebequeses y acadianos, o el tradicional papel como tierra de asilo del país, se comprende la defensa activa de la multiculturalidad del mismo, con un claro reflejo en el interior de las ciudades. Existe una tolerancia cultural, también étnica y a la diversidad religiosa, que se hace explícita. Así, las colectividades musulmanas, hindúes y sijs muestran sus señas de identidad en edificios comunitarios propios, en formas de vestir y en el reconocimiento de sus asociaciones por parte de todos los líderes políticos y de opinión canadienses. De hecho, una imagen que normalmente sorprende al viajero foráneo en las calles de esta nación de Norteamérica en período electoral es la abundancia de candidatos de origen chino, africano, griego, indio o polaco, entre otros, en las candidaturas de los diferentes partidos (conservador, liberal, nuevo-demócrata o bloque quebequés). Las tradicionales bases de la diferenciación social y grupal urbana tantas veces estudiadas (Pacione, 2001; Lois, González Pérez y Escudero, 2012), aparecen muy atenuadas en la ciudad canadiense, que en todo caso hace gala de multiculturalismo e integración.

Para demostrar esta afirmación final vamos a comentar (y esto constituye una verdadera novedad) cómo se organizan los datos culturales y étnicos de los habitantes de las principales poblaciones del país, según el organismo estadístico oficial de Canadá. Así, en el censo de población (y comentaremos los datos correspondientes a 2006) de las ciudades disponemos de dos series estadísticas que clasifican a la población por grupos y, con mayor precisión, por los denominados grupos étnicos. A este respecto, se debe subrayar que este tipo de informaciones están prohibidas en muchos países, dada su tradicional utilización con fines racistas o proclives a la segregación (Moerdijk, 1982), algo que no ocurre en Canadá, donde precisamente esta ordenación de los datos oficiales se realiza 
como base para defender los derechos comunitarios de las minorías (Statistics Canadá, 2006). En concreto, y si tomamos como ejemplo la población de Calgary, sus habitantes se clasifican en más de veinte grupos divididos en dos categorías: respuestas simples (se entiende que se incluyen con una única referencia) y respuestas múltiples (población mestiza entre dos grupos). Esta adscripción se fundamenta en las afirmaciones de los propios ciudadanos al ser preguntados por el agente censal. En Calgary, de sus 1.070.295 hab. en 2006, un total de 1.021.845 se encuadran en un grupo, 22.340 entre dos y 26.110 se identifican como población aborigen (amerindia), que recibe una consideración y protección especial. Entre las respuestas simples obtenemos una mayoría de población blanca (802.390 hab.), seguida de los chinos y los sudasiáticos con más de 50.000 personas, de los negros, filipinos, lationamericanos, sudoesteasiáticos y árabes entre 10.000 y 50.000, y otros colectivos minoritarios (del oeste de Asia, japoneses, coreanos, etc.). Dentro de las respuestas múltiples sobresalen los mestizajes de blanco y chino, blanco y sudasiático, blanco y negro, blanco y filipino, y otras muchas posibilidades más. En una estadística paralela, este origen racial o étnico diverso se especifica con mayor desagregación, ya que el censo también diferencia las personas de origen británico, francés, aborigen, otras procedencias norteamericanas, caribeño, latinoamericano, otros europeos, y así en un recorrido que sorprende por su exhaustividad. A este respecto, nos hemos preguntado cómo se elabora la clasificación publicada y las notas metodológicas del censo nos aclaran que son las propias personas quienes indican este dato. De hecho, en el recuento de Calgary se contabilizan 14.635 habitantes de origen español y 115 vascos, que se han declarado así, al margen de la primera categoría.

Si continuamos con el repaso a los abundantes registros que proporciona el censo de población en ámbitos urbanos, nos encontramos con que el mismo también diferencia a las personas que tienen por primera lengua el inglés o el francés. Aunque en Calgary los resultados son contundentes, considerando el carácter marcadamente anglófono de la provincia de Alberta (1.029.780 personas con el inglés como primer idioma frente a 16.235 con el francés y 4.110 con uso indistinto de ambas), el respeto a la colectividad francófona es exquisito, con la existencia de una delegación provincial de la radio televisión pública canadiense en este territorio ( $\mathrm{CBC}$ ), que desde Edmonton emite todo el día en este idioma oficial que apenas habla el 1\% del total de la población. De hecho, Canadá siempre se ha mantenido orgulloso por su comprensión hacia las culturas minoritarias, dando un ejemplo único a nivel mundial (Breton, 1979). A este respecto, los datos del censo se extienden por decenas de páginas en cada ciudad para contabilizar a los habitantes que hablan otras lenguas, que las emplean en sus casas, con sus amigos o sólo en algunos ámbitos concretos. De nuevo, para 
Calgary se aplica la clasificación idiomática general utilizada en este país norteamericano y que contabiliza 90 lenguas diferentes, de las cuales 74 poseen algún hablante (a veces sólo 10, en función de los datos del censo) dentro de la ciudad. En todo caso, las más importantes son el chino con 27.360 personas que lo utilizan, el punjabi con 21.190, el cantonés con 18.520, y el alemán y el español con más de 14.000 hablantes para cada uno. Por último, en este repaso sobre la atención del censo canadiense en reivindicar la multiculturalidad, los datos oficiales disponibles, ahora de 2001, se acompañan de una cartografía urbana detallada donde se representa la localización de las minorías urbanas en un mapa distrital de la ciudad. De nuevo, y esta vez mediante el recurso llamativo a la cartografía urbana, se insiste en el concepto de urbe multicultural, un calificativo que debe entenderse como defensa de la visibilidad de otros grupos, otras lenguas y otras culturas frente a las mayoritarias blanca, de origen europeo y anglófona.

Es posible abordar un último acercamiento a esta idea utilizando, una vez más, los registros censales de 2006. Así, mediante su consulta se ha elaborado la Figura 3, donde se especifica la composición étnica de Toronto, Vancouver y Calgary. La principal conclusión que se obtiene de su observación es el predominio de la población blanca, moderado en Toronto y Vancouver, junto a la presencia de minorías de origen asiático importantes en Calgary y Toronto, y muy significativas (más de un tercio de los residentes) en Vancouver. De hecho, en esta metrópoli de la costa pacífica la colectividad china se acerca a las 370.000 personas (y unas 12.000 más mestizas con blanco), la sudasiática (entiéndase vietnamita, camboyana, malasia, laosiana y otros), 202.000, mientras que los filipinos superan los 75.000, los coreanos son 44.000 y los japoneses más de 20.000 . La imagen de ciudad multicultural de Vancouver se observa perfectamente a través de los datos, que reflejan que cerca del $40 \%$ de su efectivo demográfico lo constituye población de origen oriental. Para finalizar este breve repaso sobre la multiculturalidad urbana hemos decidido aportar otra referencia estadística de la ciudad por excelencia de las minorías, Toronto. En esta gran metrópoli de Canadá tan solo 1.331.485 residentes de los más de cinco millones se identifican por sus orígenes británicos frente a 243.000 de padres francófonos, más de 57.000 aborígenes, 305.000 caribeños, 105.000 latinoamericanos, 259.000 alemanes, 95.000 holandeses, 207.000 polacos, 102.000 rusos, 122.000 ucranianos, 466.000 griegos, 188.000 portugueses, 141.000 judíos, 537.000 chinos, más de 500.000 indios y 181.000 filipinos, por citar sólo a las principales comunidades. Por eso, no debe sorprender la existencia de una ciudad cuya estructura alberga un chinatown, japantown, barrio indio, sij, portugués, italiano, griego, ruso o ucraniano, entre más de veinte colectividades con procesos visibles de apropiación de ciertas partes del entramado urbano. El calificativo multicultural 
es plenamente aplicable a las urbes de este país norteamericano, donde la convivencia personas con orígenes dispares, la preservación del multilingüísmo y la visibilidad de las minorías son considerados atributos que enriquecen a todas las ciudades, en especial las principales metrópolis del país.

Figura 3. Composición étnica de Calgary, Toronto y Vancouver.
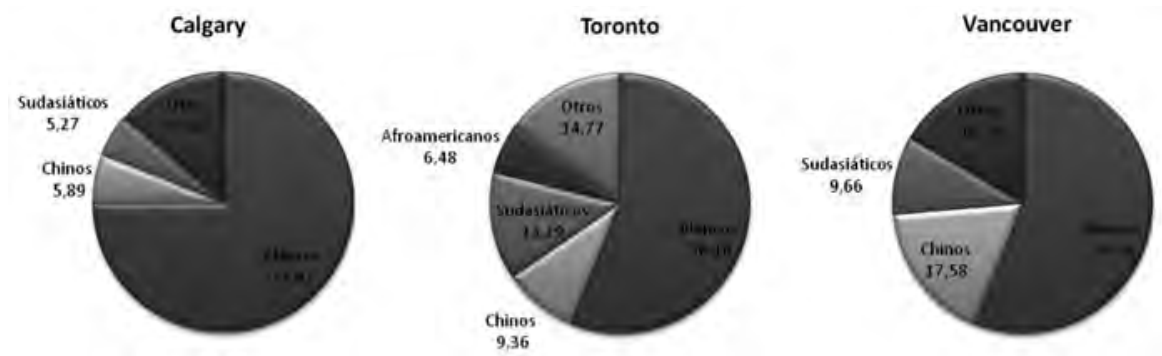

Fuente: Censos de Población. Statistics Canada. http://www.statcan.gc.ca

\section{LA ORGANIZACIÓN INTERNA DEL ESPACIO URBANO}

Desde una perspectiva europea resulta muy difícil comprender la morfología y estructura de la ciudad canadiense (norteamericana en general), a pesar de que los libros o numerosos documentales nos acerquen a las claves para interpretar su organización (a este respecto, recomendamos la consulta de Davies y Herbert, 1993, y Knox, 1994). La urbe canadiense, como su homóloga estadounidense, posee un centro urbano perfectamente reconocible por su desarrollo en altura, por su perfil en el cielo o sky line (Zoido, De la Vega, Morales, Mas y Lois, 2000). El mismo fue creado por la construcción de los primeros rascacielos en Manhattan o Chicago a finales del XIX y principios del XX, y se extendió rápidamente como modelo a toda América del Norte. En Canadá, con diferentes formas y estilos arquitectónicos, el sky line aparece en todas las ciudades principales a las que nos hemos referido. Con una silueta muy moderna en Calgary o Vancouver, un poco más tradicional en Edmonton o Montreal, y remarcando el carácter de gran centro metropolitano de Toronto. Respecto a la presencia de este centro reconocible y percibido por los ciudadanos, apuntar dos ideas. La primera, que la existencia de un downtown formado por rascacielos expresa la importancia marginal y/o la destrucción que ha sufrido el centro histórico de la población. De hecho, en esta parte de la urbe se conservan casi siempre algunos ejemplos emblemáticos de los primeros tiempos de la localidad, el ayuntamiento, alguna iglesia, comercio singular o monumento de interés local, pero en todos los casos como edificios aislados en un conjunto en el que predominan las construcciones muy modernas en altura. El casco antiguo no es reconocible en casi ningún caso. 
A lo sumo, en ciertas ciudades se llega a conservar uno o varios barrios residenciales en el centro (o sus proximidades) ocupados por población de clase trabajadora, que reside en modestas viviendas individuales, dispone de comercios de proximidad y cuenta con una antigüedad en torno a un siglo (estaríamos ante los ejemplos de los Strathcona en Vancouver, Victoria, Toronto o Edmonton, levantados entre finales del XIX y principios del XX). La segunda idea se refiere a los edificios que singularizan al downtown, que son normalmente rascacielos ocupados por grandes compañías privadas, construcciones conmemorativas y nacidas para reafirmar su carácter singular (las torres de Toronto o Calgary), y un tercer grupo reservado a la instalación de instituciones públicas (ayuntamiento, corte de justicia, asociaciones de alguna colectividad, etc.). También nos encontramos con grandes centros comerciales, muchos de ellos comunicados por vías subterráneas (para que sigan funcionando todo el invierno) y edificios de oficinas. El comercio y los despachos son concebidos para atraer a los visitantes foráneos o como negocios exclusivos (firmas de abogados prestigiosas, muy especializadas, etc.), ya que en toda la urbe se repite la presencia de establecimientos minoristas y oficinas agrupados en torno a determinados puntos centrales y accesibles de cada distrito, barrio o comunidad. El centro es el lugar de referencia obligada para los turistas y las gentes de negocios que están en la ciudad, en buena medida porque concentra una parte no despreciable de la planta hotelera. Sin embargo, la mayoría de la población de la propia urbe apenas los frecuenta, dado que su área de residencia les proporciona todas las posibilidades de compra y servicios que necesitan en su vida cotidiana. Por último, la mayor o menor presencia de edificios públicos y privados en el downtown expresa en las diferentes ciudades la importancia adquirida por cada uno de estos sectores en la dinámica urbana (por ejemplo, en Otawa y las capitales provinciales es visible un buen número de construcciones públicas emblemáticas que albergan instituciones, mientras en Calgary destaca la radicación de sedes de compañías petroleras y en Vancouver de las relacionadas con la actividad comercial y portuaria) (Figura 4).

Si salimos del centro, gran parte del espacio urbano restante es ocupado por sectores residenciales de baja densidad, constituidos en su mayoría por viviendas unifamiliares (Davies y Murdie, 1991; Davies, 1995; Davies, Chan y Townshend, 1999; Townshend, 2002). La población canadiense coincide con otras sociedades anglófonas por un marcado individualismo en su modo de vida, que se manifiesta en una opción muy mayoritaria por vivir en una casa propia, frente a una vivienda colectiva. Estas últimas, y en particular los edificios divididos en pisos o apartamentos, existen en todas las ciudades de Canadá, pero su significación es muy minoritaria. Una forma novedosa de residencia colectiva viene dada por las nuevas urbanizaciones destinadas al colectivo de mayores 
Figura 4. Skyline de Calgary.

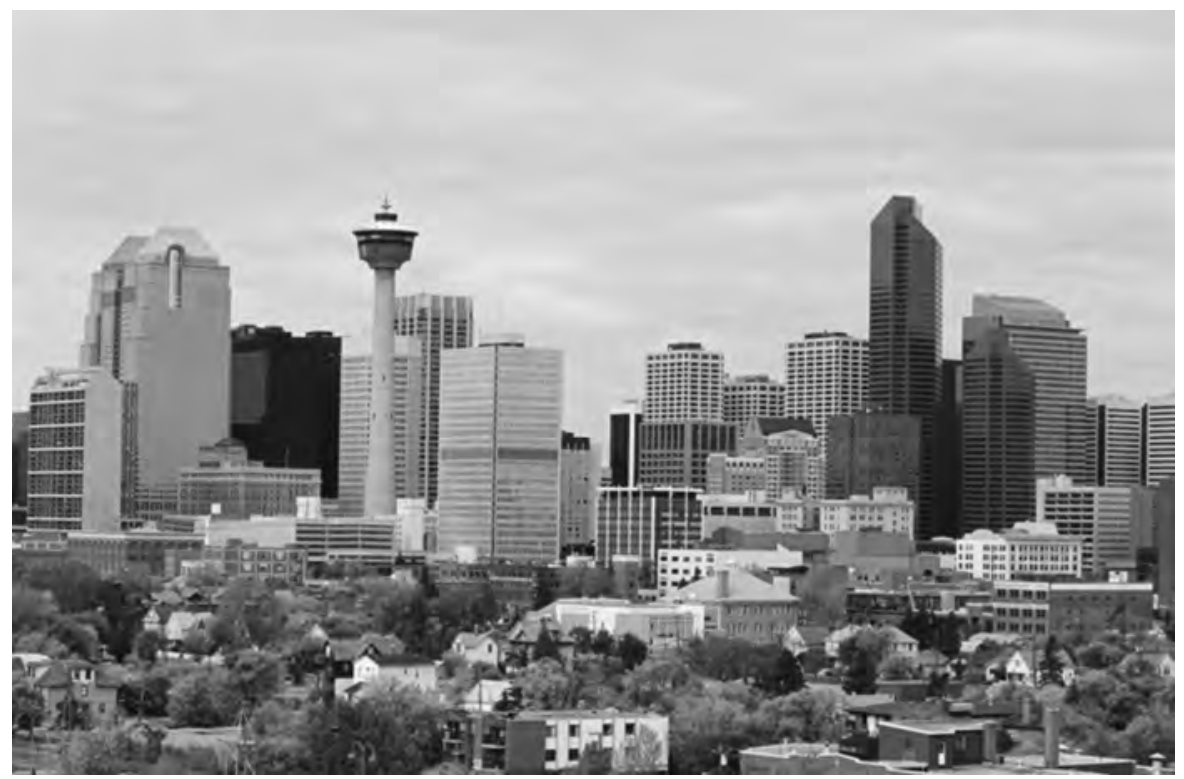

Fuente: Google Images

(seniors), que a partir de su jubilación, o un poco antes, deciden vivir en común para garantizarse unos servicios sociales compartidos y una asistencia mutua en momentos de dificultad. Estas áreas especializadas, destinadas tan solo a los mayores de 55 años de edad, aparecen en todas las poblaciones canadienses de cierta entidad, en un fenómeno que se ha generalizado en los últimos tiempos. Por lo que se refiere a las comunidades residenciales mayoritarias, las mismas oscilan entre los barrios históricos, entre ellos los Strathcona a los que nos referimos y multitud de ejemplos del denominado New Urbanism, que tanto éxito ha tenido en los países anglosajones en los dos últimos decenios (Lois, González y Escudero, 2012). Las áreas más antiguas normalmente acogían y acogen a la clase trabajadora, que gracias a sus sindicatos o a empresas cooperativas definió en un principio su proyecto residencial, hoy en día situado en espacios próximos al centro. En algunos casos, estos sectores han registrado procesos de ocupación por habitantes de clase media y acomodada, en típicos modelos de gentrificación de determinados sectores urbanos. No obstante, lo que más llama la atención es cómo han proliferado nuevas comunidades residenciales con nombres como New Scotia, Blue Lake o Red River, entre otras que bajo presupuestos postmodernos intentan recrear la vida en una antigua localidad, eso sí con un centro 
comercial propio, pequeñas tiendas, plazas, espacios verdes de paseo, edificios lujosos exentos, otros pareados e incluso divididos por pisos, definiendo unidades completamente independientes (y autosuficientes), respecto al resto de la ciudad. Cada comunidad atrae a un tipo específico de compradores, reafirma la idea de una ciudad fragmentada y segregada (que tan bien han caracterizado (W.K.D. Davies, L. Bourne o I. Townshend), que apenas muestra flujos de comunicación entre sus diversas partes. A cada comunidad se accede en coche particular, también se sale utilizándolo, aunque nos encontremos con algún medio trasporte público complementario. La ciudad es el resultado de una adicción de comunidades con fuerte autonomía, con un centro que no ejerce como tal, y donde el modo de vida individualista puede desarrollarse habiendo footing, pasando muchas horas en la vivienda propia, yendo en automóvil al trabajo y a comprar regularmente al mall local (Figura 5).

Figura 5. Área residencial de Calgary.

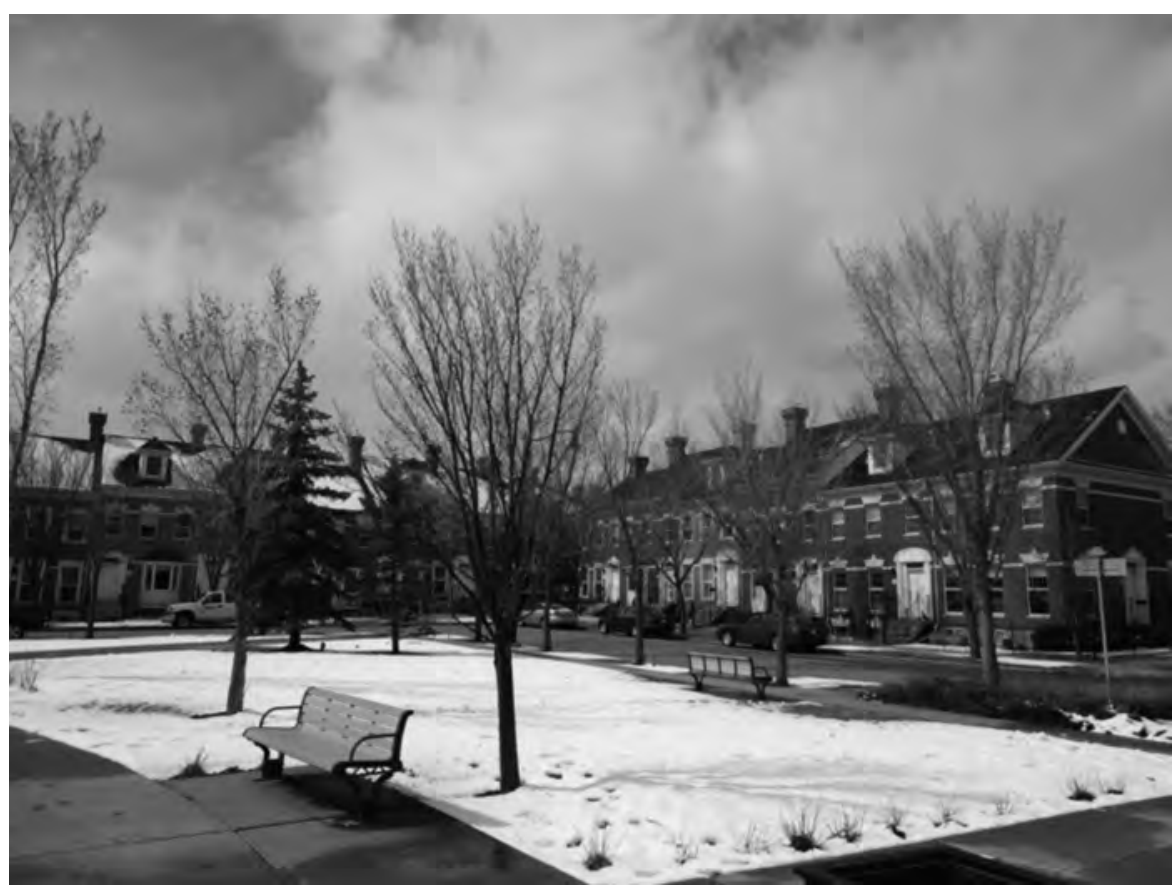

Fotografía: R. Lois

Sin duda, el urbanismo comercial de la ciudad canadiense coincide con el modelo norteamericano en general, que se ha transferido a Europa en los últimos años (Jones y Simmons, 1993; Simmons y Zsigivics, 2001; Simmons, 2002; 
Escudero, 2008). Así, en cada área de la ciudad se acostumbra a instalar un centro comercial (un mall) normalmente articulado a partir de un gran hipermercado, que concentra todo tipo de tiendas en su interior. En los bordes de esta promoción inmobiliaria única, se sitúan restaurantes, algún hotel o motel, oficinas de alquiler de coches o ciertos pubs de dimensiones respetables. Los habitantes de la comunidad próxima acuden al mall local a realizar sus compras cotidianas o alguna extraordinaria, a tomar un café o a comer sentándose en un espacio público central rodeado de pequeños restaurantes temáticos (griego, italiano, mexicano, japonés, coreano, chino, hamburguesería, etc.). Estos centros comerciales son espacios cubiertos y, en un número no despreciable de casos, subterráneos, ya que las muy bajas temperaturas invernales y primaverales en Canadá dificultan el funcionamiento de los establecimientos minoristas en el exterior. De hecho, los mismos tampoco poseían tanta tradición como en la urbe europea, puesto que nos encontramos ante unas poblaciones muy nuevas y los que existían en barrios tradicionales han desaparecido frente al empuje de los mall o se mantienen como ejemplos relictos en sectores muy característicos de la ciudad (un viejo barrio italiano, portugués o chino, un distrito próximo al centro, etc.). Como sucede en muchos ejemplos próximos a nosotros, en cada ciudad se han levantado varios malls de dimensiones espectaculares, que atraen tanto a los consumidores urbanos como de sus periferias. Aquí el comercio es más especializado (con numerosas tiendas de ropa y moda, muchas de ellas tematizadas) y el entorno constructivo donde se instala debe ser llamativo, para combinar la actividad propia de compra con la de ocio para distintos colectivos. Como apuntamos, en el downtown siempre aparecen centros comerciales, extendidos entre edificios intercomunicados o subterráneos, que normalmente ofrecen una estética más convencional y concentran tiendas de moda, algunas de ellas de grandes firmas de lujo. El atractivo de estos malls céntricos es su enorme accesibilidad.

Hacia el exterior de la ciudad siempre nos encontramos, y dicha estructura también vincula el urbanismo europeo y el norteamericano, con un conjunto de espacios ocupados por grandes superficies minoristas orientadas a distintos productos (alimentación, muebles, venta de automóviles, etc.) y áreas industriales delimitadas. Estos usos del suelo son perceptibles en las carreteras, avenidas y autopistas de entrada y salida a las ciudades, y en zonas contiguas donde se han establecido parques empresariales. La urbe canadiense apenas posee fábricas o lugares de producción en su interior. Este hecho deriva, una vez más, de la escasa trayectoria histórica de la misma; también de la evidencia de que numerosas industrias se vinculan a la transformación directa de los recursos del territorio (agroalimentarias, químicas, mecánicas, etc., derivadas de la riqueza agrícola y ganadera, de materias primas minerales o de fuentes de energía) y que, por lo 
tanto, su emplazamiento en los accesos a una ciudad sea lógico. Las normas de seguridad empresarial son estrictas y la gran disponibilidad de espacio existente permite que no estén nunca próximos dos usos del suelo incompatibles (por ejemplo, la industria pesada y la residencial).

Para finalizar, cabe preguntarse brevemente sobre los procesos de periurbanización y metropolitanización detectados. En primer término, se debe afirmar que los mismos son menos llamativos, puesto que la propia estructuración de la ciudad central en múltiples comunidades autosuficientes justifica que una buena parte del hábitat que en Europa calificaríamos como periurbano, forme parte de la ciudad central. Más allá del límite del gran municipio urbano, se repite la sucesión de comunidades autosuficientes, segregadas por nivel de renta y con perfiles residenciales muy nítidos en un conjunto de núcleos satélites que proliferan en los bordes de las autopistas o carreteras de proximidad. Los fenómenos de periurbanización son más frecuentes en contextos de mayores densidades demográficas como los entornos de Toronto o Vancouver, pero siempre generados a partir de una enorme disponibilidad de espacio para los crecimientos constructivos y de repetición de las fórmulas constructivo-sociales comentadas para la ciudad. En estas áreas también se imita el modelo comercial, centralizado por malls ya comentado y la existencia de zonificación en las afueras para las localizaciones industriales y/o empresariales. Por último, con respecto a los procesos de metropolitanización ya se ha apuntado que en las inmediaciones de las grandes urbes millonarias (de Toronto a Edmonton u Otawa, Calgary, Montreal y Vancouver) se han generado crecimientos urbanos de ámbito regional o al menos supralocal. Es correcto referirse a la creación de áreas metropolitanas típicas, pero siempre en territorios con unos niveles de densidad de población y edificativas muy inferiores a los ejemplos europeos que conocemos.

\section{EL ESTILO DE VIDA EN LA CIUDAD: LA IMPORTANCIA DEL INDIVIDUALISMO Y LA COMUNIDAD DE REFERENCIA}

Entre las características que sirven para definir lo urbano, ya desde los trabajos de la Escuela de sociología y antropología de Chicago se destacó un modo de vida específico (Wirth, 1938). Por eso, el análisis de los ritmos cotidianos de existencia en las ciudades de Canadá seguirá este modelo teórico perfectamente aplicable. Así, por una parte la vida urbana implica competitividad, individualismo, segmentación de roles, mayores posibilidades de promoción social, estructura de clases, secularización, anonimato y sensación de libertad, ocho atributos en los que nos fijaremos, sin olvidarnos de la importancia que adquiere la comunidad de referencia (sea étnica o simplemente residencial) en los espacios ciudadanos de este país de América del Norte. 
Si comenzamos centrándonos en la competitividad, la misma es consustancial a toda Norteamérica, sin duda más acervada (y esto es repetido por muchos canadienses) en Estados Unidos. Las personas trabajan un gran número de horas, procuran progresar en su puesto de trabajo o luchan por conseguir que su empresa o negocio vayan bien. Toda la publicidad y los referentes icónicos de la sociedad de la información aluden al mito del progreso a partir del propio emprendimiento y esfuerzo personal (Castells, 1989). La competitividad se desarrolla en un contexto de pleno empleo, flexibilidad laboral acrecentada y bajo una cultura que otorga un extraordinario valor al dinero. Sin lugar a dudas, la otra cara de esta realidad es el individualismo. Al mismo hemos aludido cuando comentábamos la importancia otorgada a la vivienda propia, a los desplazamientos en automóvil particular y, ahora añadimos, a la comida rápida, incidental, en el exterior, o a las prácticas muy personales de compra en los mall próximos al domicilio. La persona y su familia son el eje central de la vida de los ciudadanos canadienses que, no obstante y a diferencia de sus vecinos de Estados Unidos, consideran fundamental el mantenimiento del estado del bienestar en lo que hace referencia a la educación, sanidad pública y servicios sociales, y muestran una actitud favorable al disfrute inmediato del dinero obtenido en su trabajo, como se constata con la enorme propensión a viajar de los habitantes de este país, desde abril hasta octubre, en escapadas frecuentes al extranjero o grandes viajes a otros continentes; un comportamiento que, de nuevo, los separa de los estadounidenses que apenas salen al exterior (sólo un 15\% de los ciudadanos de esta gran potencia mundial dispone de pasaporte).

La tercera característica enumerada es la segmentación de roles, muy evidente entre los habitantes de las ciudades de Canadá, que habitan espacios urbanos bien delimitados e identificados, se desplazan a sus puestos de trabajo codificados utilizando normalmente el vehículo particular, y compran siguiendo las pautas culturales propias de su sociedad. La vida doméstica, laboral y de ocio aparecen perfectamente reguladas, y en cada una de ellas los individuos desarrollan un papel específico. Una persona encuentra a una multitud de conocidos y a otros individuos a lo largo del día, gentes con las que mantendrá tan solo un contacto superficial. Su círculo de amigos y familiares es estrecho, como corresponde a un modo de vida marcado por el individualismo. En este contexto, el esfuerzo propio, la competitividad y la visión del negocio pueden favorecer procesos relativamente rápidos de enriquecimiento y una sensible mejora en el estatus social. El aumento del nivel de renta es un fenómeno generalizado en un Canadá enormemente rico y que ha crecido en términos económicos mucho durante los últimos decenios. Se ha generalizado la clase media, y en determinadas metrópolis (Toronto y Montreal, como ejemplos) o en todo el pujante centro- 
oeste del país, los grupos muy acomodados son significativos. El negocio petrolero, agro-ganadero, comercial o la rentabilidad de ciertas industrias han hecho posible una promoción social ascendente generalizada en el sector privado. Al mismo tiempo, los servicios públicos se mantienen con una elevada consideración y niveles salariales altos para sus empleados (médicos, profesores, personal de la administración, etc.). Existen también ejemplos de movilidad social negativa, habitualmente vinculados a agudos problemas de alcoholismo y, en menor medida, drogadicción. El paro y los trabajos mal remunerados son infrecuentes, por lo que el empeoramiento de las condiciones de vida (expresado visualmente en las ciudades norteamericanas con los homeless) se debe más a problemas de adicción. Estamos ante un modelo en cierta medida similar a los países nórdicos europeos, donde un estado asistencial muy asentado otorga ayudas al conjunto de la población, aún cuando cientos de personas se refugien en hogares sociales o asociaciones de beneficencia, y vaguen por las calles todo el día sin rumbo fijo (este fenómeno es especialmente grave en algunas colectividades de población amerindia). Por último, la estructura de clases se hace evidente en todas las manifestaciones de vida y responde, en buena medida, a la caracterización que para la sociedad contemporánea realizó A. Giddens hace algún tiempo (Giddens, 1980).

El sexto atributo, la secularización, debe ser matizado. Por una parte, la sociedad canadiense mantiene una conducta hegemónica alejada de los parámetros y normas impuestas por la religión. Sin embargo, estamos ante una población que es más practicante de sus creencias que cualquiera de Europa (dominan diferentes variantes del protestantismo, como la iglesia unificada de Canadá, el metodismo y los evangélicos, la comunidad católica es numerosa, así como los musulmanes, hindús, sijs, confucianos, etc.), e incluso mantiene unos colectivos fundamentalistas importantes (como los mormones, los anabaptistas, ciertos grupos islámicos, etc.). En todo caso, la ciudadanía del país, y así se ha expresado, es completamente laica y respetuosa en sus manifestaciones públicas, defensora activa de la diversidad de creencias y del derecho a no creer, si bien en el ámbito privado la religión juega un papel no despreciable (no sólo identitario, sino más profundo). Por otra parte, en las urbes de esta enorme nación se verifica de forma incontestable otra de las características enunciadas por L. Wirth para el modo de vida urbano, el anonimato. En un contexto de aislamiento entre comunidades, unas personas y otras, la vida privada permanece como un refugio escasamente accesible a los demás. La casa y la familia se suelen cerrar al exterior en mayor medida que en Europa. Pero sobre todo en la vida pública a casi nadie le preocupa la existencia del otro. La ciudad es un espacio donde hacer lo que uno considera oportuno, en el que competir y progresar, sin recurrir a un perfil 
concreto y reconocible hacia los demás en una mayoría de los casos. De hecho, y así podemos terminar nuestro relato sobre las interpretaciones de la Escuela de Chicago en relación con la actualidad, la urbe norteamericana continua siendo un lugar de libertad. Cada persona tiene capacidad de trazar sus estrategias vitales, sin que nadie interfiera. Los grupos minoritarios de cualquier índole pueden expresarse a nivel público sin restricciones, y la gente se mueve en su vida cotidiana sin que las normas sociales, el vecindario, la familia o los compañeros de empresa interfieran en aquellas decisiones que se consideran propias $y$, por lo tanto, dignas de respeto.

Para finalizar este apartado tan solo queremos hacer una nueva mención a lo que supone lo individual y lo comunitario (entendido con una acepción tanto residencial como étnica), en las ciudades analizadas. La comunidad aclara el estatus social del que vive en ella, también refleja el nivel de integración grupal del individuo. Así, un recorrido por las urbes canadienses permite observar la clasificación de sus habitantes en distintos conjuntos definidos por el nivel de renta, el modo de vida, las preferencias individuales de residencia y, en definitiva, la clase de pertenencía en una población enormemente fragmentada en unidades autosuficientes. Cada sector de la misma, muestra unos perfiles diferenciales propios, pudiendo afirmarse una distinción en el uso del espacio entre las familias ricas, los distintos estratos de la clase media, la clase trabajadora y los grupos étnicos minoritarios, que se suelen agrupar, reflejando asimismo en su interior las variaciones según la capacidad adquisitiva de los hogares. En un contexto de afirmación generalizada del multiculturalismo, tampoco extraña la proliferación de barrios o distritos étnicos en todas las ciudades (chinatown, little Portugal, India, etc.). No todos los miembros de estos grupos de origen nacional viven, ni mucho menos, en estos sectores de referencia, pero los mismos ocupan espacios muy reconocibles en la ciudad, muestran gran homogeneidad en la composición de su efectivo humano y ayudan a dotar de personalidad a un modelo urbano fuertemente integrador.

\section{A MODO DE CONCLUSIÓN}

En esta contribución se han tratado de identificar los elementos más importantes de la Geografía urbana del Canadá. De forma deliberada, se ha superpuesto una aproximación basada en los estudios teóricos sobre la ciudad y la urbanización, muchos de ellos publicados en este país de Norteamérica, con una lectura experiencial, consecuencia de una estancia durante algunos meses en este territorio. La forma de abordar el discurso ha consistido en individualizar los rasgos que considerábamos más significativos para comprender los caracteres diferenciales de la urbe canadiense, enmarcada en el concepto más amplio de 
ciudad norteamericana. Así, las principales poblaciones de este país siguen creciendo, en un contexto económico expansivo, que nos resulta diferente a lo que está experimentando una Europa en crisis durante el período actual. Además, la morfología y las dinámicas de la ciudad canadiense son completamente distintas a las conocidas en España y, en particular, en la ribera norte del Mediterráneo. Estamos ante urbes muy extensas, donde se hace obligado el uso del automóvil particular, y donde una forma de vida individualista se manifiesta en múltiples aspectos. Del mismo modo, el pasado cuenta poco en estas localidades centrales, siempre definidas bajo estrictas normas de zonificación. La ciudad se reconoce en su sky line, aunque el centro urbano sea poco frecuentado por los habitantes de la propia urbe; una localidad en la que el número de habitantes puede variar, pero no su estructuración en comunidades residenciales autosuficientes que se extienden por la mayoría del espacio edificado.

Sin lugar a dudas, es posible identificar hasta cinco ideas fundamentales que se extraen de la caracterización de la ciudad canadiense que se ha abordado. La primera, que nos hallamos ante unos ejemplos definidos por las bajas densidades en comparación con cualquier ejemplo europeo que tomemos como referencia. En segundo término, Canadá muestra uno de los modelos más claros a nivel mundial de sociedad multiétnica y multicultural, que se afirma en las propias normas legales de este país. Incluso el sistema urbano del mismo aparece condicionado por este respeto a lo diferente, a las minorías, con un sistema de ciudades autónomo de Quebec o del conjunto de los espacios francófonos, y un enorme atractivo de ciudades occidentales como Vancouver para la población de origen asiático. En tercera instancia, la ciudad pierde protagonismo debido a la importancia adquirida por las comunidades que la integran. Se ha repetido, estamos ante ejemplos muy claros de ciudad fragmentada. En cuarto lugar, el individualismo norteamericano aparece en muy diversas manifestaciones del modo de vida de la ciudad. Entre ellas, el absoluto predominio de la vivienda unifamiliar, del uso del automóvil privado, prácticas visibles como el footing a lo largo del día o el espíritu competitivo que domina en la vida laboral. Por último, la contemporaneidad de las ciudades les hace perder algunos signos de identidad reconocibles en el paisaje urbano, lo que refuerza el papel cumplido por el centro desarrollado en altura y obligado a definir una silueta monumental de edificios muy modernos, a través de la poderosa imagen que proyecta el sky line.

\section{BIBLIOGRAFIA}

Bertrand, J.-R. y Sanguin, A.-L. (1994): «Amerique du Nord", en Revue Norois,

Num, 161, 41 ${ }^{\text {ème }}$ année, Javier-Mars. Numero thematique. Poitiers.

Breton, R. (1979): Geografia de las lenguas. Ed. Oikos-Tau. Barcelona. 
Bourne, L. (2005): «Urban Geography in transition: A Canadian Perspective on the 1980s and Beyond», en Urban Geography in America, 1950-2000. Pp. 191-217. Ed. Routledge. New Yoek.

Castells, M. (1989): La ciudad informacional. Teconologías de la información, reestructuración económica y el proceso urbano-regional. Alianza Ed. Madrid

Davies, W. K. D. (Ed.) (1993): Canadian Transformations: Perspectives on a Changing Human Gepgraphy. Ed. CSWG. Dyfed, Wales (Reino Unido).

Davies, W. K. D. (1995): «The Power of Communities in Cities», en Acta Wasaensia, No. 45, Geography 6. Pp. 49-73.

DAviES, W. K. D. y Murdie, R. A. (1991): «Consistency and Differential Impact in Urban Social Dimensionality: Intra-Urban Variations in the 24 Metropolitan Areas in Canada», Urban Geography 12 (1). Pp. 55-79.

Davies, W. K. D. y Herbert, D. (1993): Communities within cities: An Urban Social Geography. Belhaven Press. Londres.

Davies, W. K. D., Chan, J. y Townshend, I. J. (1999): «How Do Communities Differ? Empirical Evidence for Behavioral and Cognitive-Afective Dimensions of Community», in Problems in A. Aguilar y I. Escamilla (Eds.), Megacities: Social Inequalities, Environmental Risk and Urban Governance. Pp.529542. Ed. Instituto de Geografía, Universidad Nacional Autónoma de México (UNAM). México D.F.

Escudero Gómez, L. A. (2008): Los centros comerciales, espacios postmodernos de ocio y consumo: un estudio geográfico. Ed. Universidad de Castilla-La Mancha. Cuenca. Giddens, A. (1980): Sociología. Ed. Alianza Universidad. Madrid.

Jones, K. y Simmons, J. (1993): Location, Location, Location: Analyzing the Retail Environment. Ed. Nelson Canada (2 ${ }^{\mathrm{a}}$ Ed.). Toronto.

Knox, P. (1994): Urbanization. An Introduction to Urban Geography. Ed. Prentice Hall. Englewood Cliffs (New Yersey).

Limonad, E., Haersbaert, R. y Moreira, R. (orgs.) (2004): Brasil Século XXI, por uma regionalizaçao?. Ed. Max Limonad. São Paulo.

Lois González, R. C., González Pérez, J. M. y Escudero Gómez, L. A. (2012): Los Espacios Urbanos. El estudio geográfico de la ciudad y la urbanización. Ed. Biblioteca Nueva. Madrid.

Moerdijk, D. (1982): Antidesarrollo. Suráfrica y sis bastustanes. Ed. del Serbal y UNESCO. Paris.

Pacione, M. (2001): Urban Geography. A global perspective. Ed. Routledge. Londres. Statistics Canada (2001, 2006 y 2011): Census of Population. Otawa. Canadá Simmons, J. (2002): «Monitoring Changes of Commercial Structure in Canadá», en W.K.D. Davies y I.J. Townshend (Ed.), Monitoring Cities: International Perspectives. Pp. 345-357. Urban Commision of IGU y University of Calgary. Calgary. 
Simmons, J. y Zsigivics, G. (2001): «Locations Strategies of Canada Commercial Firms», Research Note 10. CSCA Website/Research/Jim/index.html.

Townshend, I. (2002): «Monitoring Community Dimensions. City-Wide Characteristics and Differentiation by Social Type Area», en W.K.D. Davies y I.J. Townshend (Ed.), Monitoring Cities: International Perspectives. Pp. 435461. Urban Commision of IGU y University of Calgary. Calgary.

WirTh, L. (1938): «The urbanism as a way of life», en The American Journal of Sociology, XLIV. Pp. 1-24. University of Chicago Press. Chicago.

Zoido, F; De La Vega, S.; Morales, G.; Mas, R. y Lois, R. C. (2000): Diccionario de Geografía urbana, urbanismo y Ordenación del Territorio. Ed. Ariel. Barcelona. 